\title{
Response surface optimization of phosphorus species adsorption onto powdered alum sludge
}

\author{
J.F. FU, Y.Q. ZHAO ${ }^{*}$, M. RAZALI, M. BRUEN \\ Centre for Water Resources Research, School of Architecture, Landscape and Civil \\ Engineering, University College Dublin, Belfield, Dublin 4, Ireland
}

\section{ABSTRACT}

The purpose of this study is to optimize adsorption conditions of powdered alum sludge (PAS) as low-cost adsorbent for the removal of three P-species (ortho-P, poly-P and organic-P) from wastewater using the response surface methodology (RSM). Initially, RSM in the basis of a three-variable Box-Behnken design was used to determine the effect of $\mathrm{pH}$ (from 4 to 7 ), PAS mass (from 0.1 to $0.5 \mathrm{~g}$ ) and PAS particle size (from 125 to $420 \mu \mathrm{m}$ ) on the response levels (removal efficiencies of the three P-species). Three response surface quadratic models in terms of three factors were then obtained from an analysis of the experimental data using a SAS computer package. Thereafter, the effect of each of the parameters on $\mathrm{P}$ removal for each of the three species was examined using the three-dimensional response surface. All three

Address correspondence to Y. Q. Zhao, Centre for Water Resources Research, School of Architecture, Landscape and Civil Engineering, Newstead Building, University College Dublin, Belfield, Dublin 4, Ireland; Phone: +353-1-7163215, Fax: +353-1-7163297; E-mail: yaqian.zhao@ucd.ie 
parameters ( $\mathrm{pH}$, PAS mass and PAS particle size) had a significant effect on the removal of each of the $\mathrm{P}$ species. Finally, optimal conditions for $\mathrm{P}$ species removal were determined at which the P-removals of $99.8 \%$ (for ortho-P), $94.9 \%$ (for poly-P) and $94.8 \%$ (for organic-P) were achieved, respectively. The results derived from the verification experiments agreed with that predicted by the models, confirming the suitability of the established models and the success of RSM in optimizing the PAS adsorption conditions.

Keywords: Phosphorus species; powdered alum sludge; adsorption; response surface methodology; Box-Behnken design

\section{INTRODUCTION}

Phosphorus $(\mathrm{P})$ is usually considered to be the limiting nutrient with respect to the eutrophication of fresh water bodies. ${ }^{[1]}$ Excess of $\mathrm{P}$ can disturb the balance of organisms present in the water and affect water quality, mainly through the depletion of oxygen as the algae decay. ${ }^{[2,3]}$ Generally, total $\mathrm{P}$ concentrations in excess of $100 \mu \mathrm{g}$ $\mathrm{P} \mathrm{L}^{-1}$ indicate excessive nutrient enrichment in lakes. $\mathrm{P}$ usually occurs in wastewater and surface water in the form of inorganic phosphates (ortho- and poly-phosphates) and organic phosphates (e.g. detergents). In wastewater treatment technology, the removal of phosphate can be achieved by several physical (e.g. settling and filtration),

${ }^{[4]}$ chemical (e.g. precipitation, ion exchange and sorption) ${ }^{[5-7]}$ and biological methods 
${ }^{[8]}$ as well as crystallization methods. ${ }^{[9]}$ Adsorption is a promising method, especially if it can employ a low-cost adsorbent.

Alum sludge is a waste by-product generated during the production of drinking water by flocculation using an aluminum-based coagulant. It is commonly a physical mixture of aluminum hydroxides, natural organic matter (NOM), sediment, removed colours, turbidity, added aluminum sulphate and residual polymers. Alum sludge is locally and largely available and free-of-charge from drinking-water treatment plants. More significantly, recent literature has shown that alum sludge is a cost-effective amendment that reduces excess soluble $\mathrm{P}$ concentrations in water pollution control systems. ${ }^{[10-12]}$ In our study, we proposed the use of dewatered alum sludge as a novel, effective, yet highly economical sorbent or resource material for P removal. ${ }^{[13,14,15]}$ In particular, a novel use of dewatered alum sludge as a main substrate in constructed wetland for wastewater treatment has been preliminarily studied. ${ }^{[16]}$ Previous studies have identified that the P-adsorption capacity of alum sludge depends significantly on the $\mathrm{pH}$ of the phosphorus solution, adsorption being enhanced in the acidic region. ${ }^{[10-14]}$ However, a systematic study to analyse and modeling integrated effects of influencing factors, such as sludge mass, particle size and $\mathrm{pH}$, on $\mathrm{P}$ adsorption for different $\mathrm{P}$ species is lacking.

In assessing the effects of multiple parameters on treatment efficiency, the use of an adequate experimental design is particularly important. To study the interactions of two or more variables, response surface methodology (RSM) has proved a useful tool. ${ }^{[17]}$ It is a collection of mathematical and statistical techniques for designing 
experiments, building numerical models, evaluating the effects of variables and searching for the optimum combinations of factors. This methodology is more practical compared to the conventional 'one-variable-at-a-time' approaches as it arises from an experimental methodology which includes interactive effects among the variables and, eventually, it depicts the overall effects of the parameters on the process. ${ }^{[18]}$ RSM usually contains three stages: (i) design and experiment, (ii) response surface modeling through regression, (iii) optimization. The main advantage of RSM is the reduced number of experiments needed to describe the effects of multiple parameters and their interactions. ${ }^{[19]}$

In the past few years, RSM has been applied to optimize and evaluate interactive effects of independent factors in wastewater treatment processes, such as analysis of the interactive effects of cell concentration and light intensity on hydrogen production by Rhodopseudomonas capsulate ${ }^{[20]}$ application of the Box-Behnken design and RSM to the advanced treatment of fulvic acid wastewater using $\mathrm{Ti} / \mathrm{TiO}_{2}$ photoelectrocatalytic oxidation; ${ }^{[21]}$ the optimization of ozone treatment for colour and COD removal of acid dye effluent using the central composite design (CCD) and

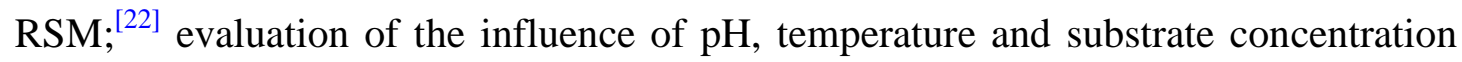
on the acidogenesis of sucrose-rich wastewater etc. ${ }^{[23]}$ However, RSM has not yet been applied to optimize the removal of $\mathrm{P}$ from wastewaters using alum sludge as an adsorbent.

Therefore, the aim of this work is to model and analyze the independent influencing variables on the adsorption of three $\mathrm{P}$-species (ortho-P, poly-P and organic-P) by 
powdered alum sludge (PAS) using RSM. Previous work by the authors indicated that the adsorption equilibrium for P-enriched solutions was reached in 24 hours. ${ }^{[14]}$ Thus, the variables considered to affect the $\mathrm{P}$-adsorption behavior in this study are the $\mathrm{pH}$ value of the P-solution, the mass of PAS, and the particle size of PAS.

\section{MATERIALS AND METHODS}

\section{PAS Preparation}

The dewatered alum sludge was obtained from the Ballymore-Eustace Water Treatment Plant located in Co. Kildare, South Dublin, Ireland. The plant uses aluminum sulphate as a coagulant to treat reservoir water (with an average colour of 105 Hazen units) via the traditional processes of flocculation, sedimentation, filtration and disinfection. General chemical and physical characterization of this sludge has been reported in an early study. ${ }^{[14]}$ After collection, the sludge (with cake moisture content of $72-75 \%$, measured via oven-dry for constant mass loss at $103 \pm 2{ }^{\circ} \mathrm{C}$ ) was air-dried and then ground and sieved to produce powder of different particle sizes. The moisture content of the prepared PASs was in the range 23.4-23.7\%. 


\section{Three Artificial P Solutions}

Three types of $\mathrm{P}$ solutions were artificially prepared to roughly simulate the P-concentrations found in typical municipal wastewater. The concentrations of the separately prepared P-solutions are 14.7 mg- $\mathrm{PO}_{4}{ }^{3-} \mathrm{L}^{-1}$ ortho-P (potassium dihydrogen phosphate: Riedel De Haen $\mathrm{KH}_{2} \mathrm{PO}_{4}$, AnalaR grade), $16.8 \mathrm{mg}-\mathrm{PO}_{4}{ }^{3-} \mathrm{L}^{-1}$ poly-P (sodium hexametaphosphate: $\mathrm{BDH}\left(\mathrm{NaPO}_{3}\right)_{6}$, no grade) and $3.3 \mathrm{mg}-\mathrm{PO}_{4}{ }^{3-} \mathrm{L}^{-1}$ organic-P (adenosine monophosphate: Fluka $\mathrm{C}_{10} \mathrm{H}_{14} \mathrm{~N}_{5} \mathrm{O}_{7} \mathrm{P} \cdot \mathrm{H}_{2} \mathrm{O}$, AnalaR grade), respectively.

\section{Procedures and Analysis}

P sorption experiments using the PAS were conducted using a batch equilibration test procedure. Known quantities of the PAS were added to $100 \mathrm{~mL}$ of the $\mathrm{P}$ species solution. The $\mathrm{pH}$ of the mixture was adjusted by adding $0.1 \mathrm{M}$ sulphuric acid. The contents were then placed in a series of $150 \mathrm{~mL}$ plastic bottles at room temperature $\left(20 \pm 2{ }^{\circ} \mathrm{C}\right.$ ) and shaken (at $200 \mathrm{rpm}$ ) for 24 hours in which equilibrium was reached. The suspension was then filtered through 0.45 Millipore membranes and the filtrate was analyzed to determine the concentration of $\mathrm{P}$ in the treated solution. Several operational parameters, such as $\mathrm{pH}$, mass and particle size of PAS were varied according to the experimental design, which is explained below. 
The residual $\mathrm{P}$ concentrations were determined according to method 8114 (HACH) using a HACH DR-2400 spectrophotometer as described in the previous study. ${ }^{[14]} \mathrm{P}$ removal efficiency $(Y)$ was defined as:

$$
Y(\%)=\frac{C_{0}-C_{e}}{C_{0}} \times 100
$$

where $C_{0}$ and $C_{\mathrm{e}}$ are, respectively, the initial and equilibrium concentrations $\left(\mathrm{mg}-\mathrm{PO}_{4}{ }^{3-} \mathrm{L}^{-1}\right)$ of $\mathrm{P}$ in solution.

\section{Experimental Design}

In RSM, the experimental design involves the selection of test levels of the independent variables for the experiments; fitting a mathematical model to the results and finally selecting optimum levels of the variables. ${ }^{[2]}$ A Box-Behnken design utilizing three levels of each of the three independent factors was used to specify the experiments. ${ }^{[25]}$ The independent factors here were $\mathrm{pH}$, mass of PAS and particle size of PAS. They are given the variable names $x_{1}, x_{2}$ and $x_{3}$ respectively and the actual values used are shown in Table 1. The experimental plan presented in Table 2 shows all the experimental designs along with the resulting removal efficiencies for each of the $\mathrm{P}$-species, ortho-P $\left(Y_{1}\right)$, poly-P $\left(Y_{2}\right)$ and organic-P $\left(Y_{3}\right)$.

[Table 1, here]

[Table 2, here] 


\section{Model Fitting and Statistical Analysis}

The coefficients of a second order polynomial model (Eq. 2) were fitted to the experimental results: ${ }^{[26]}$

$$
Y_{i}=\beta_{0}+\beta_{1} x_{1}+\beta_{2} x_{2}+\beta_{3} x_{3}+\beta_{11} x_{1} x_{1}+\beta_{12} x_{1} x_{2}+\beta_{13} x_{1} x_{3}+\beta_{22} x_{2} x_{2}+\beta_{23} x_{2} x_{3}+\beta_{33} x_{3} x_{3}
$$

where $Y_{\mathrm{i}}(i=1,2,3)$ are the removal efficiencies of PAS for ortho-P, poly-P and organic-P solutions; $\beta_{0}$ is a constant, $\beta_{1}, \beta_{2}, \beta_{3}$ are the linear coefficients; $\beta_{12}, \beta_{13}, \beta_{23}$ are the cross-coefficients; $\beta_{11} \beta_{22}, \beta_{33}$ are the quadratic coefficients and $x_{1}, x_{2}$ and $x_{3}$ are the values of the factors. The SAS (SAS Institute, Cary, NC, USA) computer program is used for the analysis of variance (ANOVA) and response surface studies. Three-dimensional response surface graphs and two-dimensional contour plots were generated using STATISTICA software (Release 5.1, Statsoft, USA).

\section{RESULTS AND DISCUSSION}

\section{Mathematical models and ANOVA analysis}

By using multiple regression analysis, the responses (removal efficiency of each of the three P-species) were correlated with the three independent variables using the second-order polynomial (Eq. 2). The coefficients of the models and their statistical significance were evaluated using the SAS program as shown in Table 3 and Table 4, 
respectively.

[Table 3, here]

[Table 4, here]

A positive sign in front of any term of the models indicates a beneficial effect (i.e. enhanced removal of $\mathrm{P}$ ) while a negative sign indicates an adverse influence. Note that the zero values for $\beta_{3}$ suggest that the principle influence of particle size is linear. The quality of the fitted models is indicated by their correlation coefficient $\left(R^{2}\right)$ and absolute average deviation (AAD). ${ }^{[19]}$ The $R^{2}$ values for $Y_{1}, Y_{2}$ and $Y_{3}$ were 0.9926 , 0.9918 and 0.9993 , respectively. This is confirmed by the plots of predicated values versus experimental values in Fig. 1, which indicates that the models adequately explain the experimental range studied. In addition, AAD values were important to measure the model's accuracy, and were calculated by Eq. (3) as $2.68 \%, 6.65 \%$, and $1.08 \%$ for the three models.

$$
A A D=\left\{\left[\sum_{i}^{p}\left(\left|Y_{i, \exp }-Y_{i, c a t}\right| / Y_{i, \exp }\right)\right] / p\right\} \times 100
$$

where $Y_{\mathrm{i}, \text { exp }}$ and $Y_{\mathrm{i}, \mathrm{cal}}$ are the experimental and calculated responses, respectively, and $p$ is the number of experimental runs.

Generally, $R^{2}$ should be close to 1.0 and the AAD between the predicated and observed data should be as small as possible. ${ }^{[27]}$ These $R^{2}$ and AAD values for the three models indicate that the model equations are adequate to describe the experimental results. 
The utility of the three models was further confirmed through an ANOVA analysis. ANOVA is a statistical technique that subdivides the total variation in a set of data into component parts associated with specific sources of variances for the purpose of testing hypotheses on the parameters of the model. ${ }^{[28]}$ The results of ANOVA for the three models are given in Table 4. It is clear that the three models are highly significant, with $\mathrm{F}$ values of $74.9698,67.1970$ and 755.86 respectively and have very low probability values $(P>F=0.0001,0.0001,0.0001)$. $P$ values lower than 0.01 indicate that the models are considered to be statistical significant. ${ }^{[27]}$

[Fig. 1, here]

[Table 4, here]

\section{Effects of Parameters with Response Surface and Contour Plotting}

Three-dimensional response surface and two-dimensional contour plots relating the removal efficiency of each $\mathrm{P}$ species with the independent factors were produced using the STATISTICA computer program, as shown in Figs. 2-4. They provide a visible indication of the complex relationships between the dependent $\left(Y_{1}, Y_{2}, Y_{3}\right)$ and independent variables $\left(x_{1}, x_{2}, x_{3}\right)$. Since each plot can show only two independent variables, one variable was held constant for each diagram. Thus, a total of nine diagrams were produced. All three factors, $\mathrm{pH}$, PAS mass and PAS particle size had significant effects on the response, i.e. P removal. However, the interaction between $\mathrm{pH}$ and PAS mass and between $\mathrm{pH}$ and PAS particle size were less significant. The shapes of contour plots indicate the nature and extent of the interactions as well. 
Prominent interactions are shown by the elliptical nature of the contour plots while less prominent or negligible interactions would otherwise be shown by the circular nature of the contour plots.

[Fig. 2, here]

[Fig. 3, here]

[Fig. 4, here]

Figs. 2-4 clearly show the adsorption process is better in acidic suspensions than in alkaline suspensions for all types of PAS. The adsorption efficiencies are higher at $\mathrm{pH}$ 4, followed by 5.5 and 7 . This could be due to more $\mathrm{OH}^{-}$ions in the suspension occupying the active sites on the surface of the PAS, forming a counter ion layer that reduces phosphate adsorption. $\mathrm{OH}^{-}$competes strongly with phosphate for active sites when the suspension is within the alkaline range. ${ }^{[12]}$ Adsorption is better in a low $\mathrm{pH}$ medium as anion adsorption is coupled with the release of $\mathrm{OH}^{-}$ions. ${ }^{[29]}$ At a fixed volume, the amount of PAS influences the degree of adsorption as shown in Figs. 2-4. Increasing the PAS mass increases the rate of adsorption while reducing it lowers the P removal rate. Macks et al., ${ }^{[30]}$ also found that additional adsorption sites are made available when a larger amount of sludge is used, allowing even more $\mathrm{P}$ to be removed. The response surface in Fig. 3 shows that the finer PAS adsorbs more P species compared to the bigger particle sizes due to its greater surface area. Besides, finer particles are more easily distributed through the suspension, increasing the probability of collisions between PAS and phosphorous ions, ${ }^{[31]}$ and thereby increasing the rate of adsorption. The results obtained agreed with that reported by 
Zumpe et al. ${ }^{[32]}$ who claimed that particle size plays an important role in the physicochemical reactions of the adsorption process and particle size also affects the time taken to achieve equilibrium.

\section{Optimum Conditions for P Species Adsorption}

The optimization of $\mathrm{P}$ adsorption under the constrains of $\mathrm{pH}$, mass and particle size of PAS limitation in this study can be defined by the following equations that can be solved by mean of Mathematics 5.2 software (v5.2, Wolfram Research, Inc.).

$$
\begin{aligned}
& \qquad \text { Find } x=\left[x_{1}, x_{2}, x_{3}\right] \\
& \text { to maximize } \quad Y_{\mathrm{i}} \quad(i=1,2,3) \\
& \text { Subject to } 4 \leqslant x_{1} \leqslant 7, \quad 0.1 \leqslant x_{1} \leqslant 0.5, \quad 125 \leqslant x_{1} \leqslant 420
\end{aligned}
$$

The optimum parameter values (Table 5) for ortho-P, poly-P and organic-P removal were: $\mathrm{pH}, 4.20,4.27,4.17$; PAS mass, $0.492 \mathrm{~g}, 0.467 \mathrm{~g}, 0.471 \mathrm{~g}$; PAS particle size, $125 \mu \mathrm{m}, 125 \mu \mathrm{m}, 125 \mu \mathrm{m}$. The corresponding P-species removal efficiencies are respectively $99.8 \%, 94.9 \%$ and $94.8 \%$. Note that the optimization gave particle sizes on the specified lower limit of our investigation $(125 \mu \mathrm{m})$ for all three P-species, corresponding to the range of experimental results. It is possible that if additional experiments were done for even smaller particle sizes, even greater removal efficiencies may be obtained.

[Table 5, here] 


\section{Model Verification and Confirmation}

In order to confirm the model's ability to predict the maximum three P-species removal efficiency, four runs of confirmation experiments are performed using the calculated optimum operation conditions (Table 5). The resulting removal efficiencies were close to those predicted by the model, with percentage errors for ortho-P, poly-P and organic-P of $0.2 \%, 3 \%$ and $0.7 \%$, respectively (Table 5). The good agreement between the predicted and experimental results verified the validity of the model and its usefulness in determining an optimal operating point. However, it should be pointed out that in real wastewater operation, adsorption could become more complicated since the background pollutants, such as other ions $\left(\mathrm{Ca}^{2+}, \mathrm{Mg}^{2+}, \mathrm{Cl}^{-}\right.$, $\mathrm{SO}_{4}{ }^{2-}$ and $\mathrm{SiO}_{4}{ }^{2-}$ ) and various organics in wastewater might affect the $\mathrm{P}$ immobilization via competitive adsorption. ${ }^{[15]}$ Thus a considerable variety in accuracy to predict the P removal using the model would be expected.

\section{CONCLUSIONS}

In this study, RSM was used to determine the optimum conditions for the removal of three different species of $\mathrm{P}$ removal by PAS. The effects of the initial $\mathrm{pH}$ of the artificial P-enriched wastewater, the PAS mass and the PAS particle size on the adsorption have been investigated and the effects of these parameters on $\mathrm{P}$ removal efficiency have been evaluated. It has been demonstrated that the RSM can be used 
for the optimization of phosphate removal from wastewater by PAS adsorption:

- The effective parameters on the removal of different species of phosphate from wastewater by PAS adsorption are initial $\mathrm{pH}$ of the solution, mass and particle size of PAS.

- The optimum conditions for the parameters of $\mathrm{pH}, \mathrm{PAS}$ mass and PAS size studied were 4.2, $0.49 \mathrm{~g}, 125 \mu \mathrm{m}$ (for ortho-P); 4.3, $0.47 \mathrm{~g}, 125 \mu \mathrm{m}$ (for poly-P) and 4.2, $0.47 \mathrm{~g}, 125 \mu \mathrm{m}$ (for organic-P), respectively. Under the optimal conditions, P removal efficiencies of $99.6 \%, 92.1 \%$ and $94.2 \%$, respectively, can be achieved.

- The predicted optimal and laboratory measured $\mathrm{P}$ removal efficiencies agreed well, with high coefficients of determination $\left(R^{2}=0.9926,0.9918\right.$ and $0.9993)$ and small AAD values $(2.68 \%, 6.65 \%$, and $1.08 \%)$. Thus, it may be concluded that the three mathematical models developed in the forms of second-order polynomial are adequate for describing the dependence of the P removal efficiencies on the various parameters.

\section{ACKNOWLEDGEMENTS}

The authors would like to thank Irish Environmental Protection Agency (Grant no: 2005-ET-S-7-M3) and the Urban Institute of Ireland for their financial support of this study. Mr. Patrick Kearney, section head technician of the Water and Effluents Laboratory, UCD, is thanked for his invaluable technical assistance during the study. 


\section{REFERENCES}

[1] Bennett, E.M.; Carpenter, S.R.; Caraco, N.F. Human impact on erodable phosphorus and eutrophication: a global perspective. Bioscience 2001, 51, $227-234$

[2] Pollution; Causes, Effects, and Control, R.M. Harrison (Ed.), third ed, The Royal Society of Chemistry, London, 1996.

[3] Kiely, G. Environmental Engineering, McGraw-Hill, New York, 1997.

[4] Clark, T.; Stephenson, T.; Pearse, P.A. Phosphorus removal by chemical precipitation in a biological aerated filter. Water Res. 1997, 31, 2557-2563.

[5] Ruixia, L.; Jinlong, G.; Hongxiao, T.J. Adsorption of fluoride, phosphate, and arsenate ions on a new type of ion exchange fiber. J. Colloid Interface Sci. 2002, $248,268-274$.

[6] Ugurlu, A.; Salman, B. Phosphorous removal by fly ash. Environ. Int. 1998, 24, 911-918.

[7] Agyei, N.M.; Strydom, C.A.; Potgieter, J.H. An investigation of phosphate ion adsorption from aqueous solution by fly ash and slag. Cement Conc. Res. 2000, $30,823-826$.

[8] Stensel, H.D. Principles of biological phosphorus removal, in: R.I. Sedlak (Ed.), Phosphorus and Nitrogen Removal from Municipal Wastewater-Principles and Practice, second ed., H.K. Lewis, London, 1991, p. 141.

[9] Moreno, E.C.; Varughese, K. Crystal growth of calcium apatites from dilute solutions. J. Cryst. Growth 1981, 53, 20-30. 
[10] Kim, J.G.; Kim, J.H.; Moon, H.S.; Chon, C.M.; Ahn, J.S. Removal capacity of water plant alum sludge for phosphorus in aqueous solutions. Chem. Speciation Bioavailability 2002, 14, 67-73.

[11] Georgantas, D.A.; Grigoropoulou, H.P. Phosphorus removal from synthetic and municipal wastewater using spent alum sludge. Water Sci. Technol. 2005, 52, $525-532$.

[12] Makris, K.C.; Harris, W.G.; O’Connor, G.A; Obreza, T.A.; Elliott, H.A. Physicochemical properties related to long-term phosphorus retention by drinking-water treatment residuals. Environ. Sci. Technol. 2005, 39, 4280-4289.

[13] Yang, Y.; Tomlinson, D.; Kennedy, S.; Zhao, Y.Q. Dewatered alum sludge: a potential adsorbent for phosphorus removal. Water Sci. Technol. 2006, 54, 207-213.

[14] Razali, M.; Zhao, Y.Q.; Bruen, M. Effectiveness of a drinking-water treatment sludge in removing different phosphorus species from aqueous solution. Sep. Purif. Technol. 2007, 55, 300-306.

[15] Yang, Y.; Zhao, Y.Q.; Babatunde, A.O.; Wang, L.; Ren, Y.X.; Han, Y. Characteristics and mechanisms of phosphate adsorption on dewatered alum sludge. Sep. Purif. Technol. 2006, 51, 193-200.

[16] Zhao, Y.Q.; Babatunde, A.O.; Razali. M.; Harty, F. Use of dewatered alum sludge as a substrate in reed bed treatment systems for wastewater treatment. Journal of Environmental Science and Health, Part A: Toxic/Hazardous Substances \& Environmental Engineering. 2008, 43, 105-110. 
[17] Box, G.E.P.; Draper, N.R. Empirical Model-Building and Response Surfaces, Wiley, New York, 1987.

[18] Bas, D.; Boyaci, I.H. Modeling and optimization I: usability of response surface methodology. J. Food Eng. 2007, 78, 836-845.

[19] Gunaraj, V.; Murugan, N. Application of response surface methodologies for predicting weld base quality in submerged arc welding of pipes. J. Mater Process Technol. 1999, 88, 266-275.

[20] Shi, X.Y.; Yu, H.Q. Response surface analysis on the effect of cell concentration and light intensity on hydrogen production by Rhodopseudomonas capsulate. Process Biochem. 2005, 40, 2475-2481.

[21] Fu, J.F.; Zhao, Y.Q.; Wu, Q.L. Optimising photoelectrocatalytic oxidation of fulvic acid using response surface methodology. J. Hazard. Mater. 2007, 144, 499-505.

[22] Muthukumar, M.; Sargunamani, D.; Selvakumar, N.; Venkata Rao, J. Optimisation of ozone treatment for colour and COD removal of acid dye effluent using central composite design experiment. Dyes Pigments 2004, 63, $127-134$.

[23] Wang, G.; Mu, Y.; Yu, H.Q. Response surface analysis to evaluate the influence of $\mathrm{pH}$, temperature and substrate concentration on the acidogenesis of sucrose-rich wastewater. Biochem. Eng. J. 2005, 23, 175-184.

[24] Myers, R.H.; Montgomery, D.C. Response Surface Methodology: Process and Product Optimization Using Designed Experiments, first ed., John Wiley\& Sons. 
Inc., New York, 1995.

[25] Box, G.E.P.; Hunter, W.G.; Hunter, J.S. Statistics for experimenters, New York, Wiley, 1978.

[26] Khuri, A.I.; Cornell, J.A. Response Surfaces: Designs and Analysis, Marcel Dekker, ASQA Quality Press, New York, 1996.

[27] Montgomery, D.C. Design and analysis of experiments, Singapore, John Wiley and Sons, Pte Ltd, 2001.

[28] Little, T.M.; Hills, F.J. Agricultural Experimental Design and Analysis, JohnWiley, New York, 1978, p. 170.

[29] Sujana, M.G.; Thukur, R.S.; RAO, S.B. Removal of flouride from aqueous solutions by using alum sludge. J. Colloidal Interface Sci. 1997, 206, 94-101.

[30] Macks, S.; Grant, C.; Murray, R.; Drew, E. Water treatment sludges for removing phosphorous from contaminated waters, $16^{\text {th }}$ International Congress in Soil Science, Montpellier, France, 1998.

[31] Makris, K.C.; Ei-Shall, H.; Harris, W.G.; O’Connor, G.A.; Obreza, T.A. Intraparticle phosphorus diffusion in a drinking water treatment residual at room temperature. J. Colloid Interface Sci. 2004, 277, 417-423.

[32] Zumpe, H.; Baskaran, K.; Dharmabalan, P. Reuse of water treatment plant sludge for phosphorous removal, $3^{\text {rd }}$ World Water Congress. 
Table list

Table 1 Factors and levels in the three-factor three-level RSM design

\begin{tabular}{ccccc}
\hline Factors & Variable name & Inferior level & Center point & Superior level \\
\cline { 3 - 5 } & $x_{1}$ & 4 & 5.5 & 7 \\
PAS mass $(\mathrm{g})$ & $x_{2}$ & 0.1 & 0.3 & 0.5 \\
PAS size $(\mu \mathrm{m})$ & $x_{3}$ & 125 & 273 & 420 \\
\hline
\end{tabular}

Table 2 The design of RSM and its actual and predicted values

\begin{tabular}{ccccccc}
\hline \multirow{2}{*}{ Run } & $x_{1}$ & $x_{2}$ & $x_{3}$ & $Y_{1}$ & $Y_{2}$ & $Y_{3}$ \\
\cline { 5 - 7 } 1 & 4 & 0.1 & 273 & 68.38 & 28.43 & 49.96 \\
2 & 4 & 0.5 & 273 & 94.73 & 79.48 & 89.18 \\
3 & 7 & 0.1 & 273 & 39.04 & 13.10 & 29.31 \\
4 & 7 & 0.5 & 273 & 84.25 & 55.36 & 64.43 \\
5 & 5.5 & 0.1 & 125 & 76.71 & 34.52 & 59.78 \\
6 & 5.5 & 0.1 & 420 & 22.34 & 8.93 & 15.90 \\
7 & 5.5 & 0.5 & 125 & 97.95 & 85.12 & 87.83 \\
8 & 5.5 & 0.5 & 420 & 81.51 & 37.50 & 58.88 \\
9 & 4 & 0.3 & 125 & 97.26 & 77.38 & 87.24 \\
10 & 7 & 0.3 & 125 & 78.84 & 55.9 & 70.09 \\
11 & 4 & 0.3 & 420 & 72.60 & 27.38 & 53.63 \\
12 & 7 & 0.3 & 420 & 48.63 & 18.45 & 29.70 \\
13 & 5.5 & 0.3 & 272.5 & 74.08 & 57.14 & 68.25 \\
14 & 5.5 & 0.3 & 272.5 & 72.71 & 55.36 & 68.36 \\
15 & 5.5 & 0.3 & 272.5 & 71.40 & 53.57 & 69.55 \\
\hline
\end{tabular}


Table 3 The estimation for three models (Coefficients are used to form Eq. (2))

\begin{tabular}{cccc}
\hline $\begin{array}{c}\text { Model } \\
\text { coefficients }\end{array}$ & Ortho-P $\left(Y_{1}\right)$ & Poly-P $\left(Y_{2}\right)$ & Organic-P $\left(Y_{3}\right)$ \\
\hline$\beta_{0}$ & +170.59 & -6.55 & +32.33 \\
$\beta_{1}$ & -18.60 & +12.08 & +10.41 \\
$\beta_{2}$ & -35.29 & +307.89 & +188.18 \\
$\beta_{3}$ & -0.16 & 0.01 & +0.02 \\
$\beta_{11}$ & +0.79 & -1.78 & -1.32 \\
$\beta_{12}$ & +15.72 & -7.33 & -3.42 \\
$\beta_{13}$ & -0.01 & +0.01 & -0.01 \\
$\beta_{22}$ & -72.94 & -181.55 & -188.34 \\
$\beta_{23}$ & +0.32 & -0.19 & +0.13 \\
$\beta_{33}$ & 0.00 & 0.00 & 0.00 \\
\hline
\end{tabular}


Table 4 ANOVA table for three responses (three P-species)

\begin{tabular}{|c|c|c|c|c|c|c|c|c|c|c|c|c|c|c|c|}
\hline \multirow{2}{*}{ Source } & \multicolumn{5}{|c|}{$Y_{1}$} & \multicolumn{5}{|c|}{$Y_{2}$} & \multicolumn{5}{|c|}{$Y_{3}$} \\
\hline & DF & SS & MS & $F$ & $P$ & $\mathrm{DF}$ & SS & MS & $F$ & $P$ & DF & SS & MS & $F$ & $P$ \\
\hline Model & 9 & 6207.94 & 689.7711 & 74.9698 & 0.0001 & 9 & 610.0053 & 8098.355 & 67.197 & 0.0001 & 9 & 6661.385 & 740.1539 & 755.86 & 0.0001 \\
\hline$x_{1}$ & 1 & 844.9996 & 844.9996 & 91.8412 & 0.0002 & 1 & 610.0053 & 610.0053 & 45.5543 & 0.0011 & 1 & 934.4748 & 934.4748 & 954.3044 & 0.0001 \\
\hline$x_{2}$ & 1 & 2885.918 & 2885.918 & 313.6643 & 0.0001 & 1 & 3718.502 & 3718.502 & 277.6921 & 0.0001 & 1 & 2642.212 & 2642.212 & 2698.28 & 0.0001 \\
\hline$x_{3}$ & 1 & 1974.156 & 1974.156 & 214.5668 & 0.0001 & 1 & 3226.721 & 3226.721 & 240.9666 & 0.0001 & 1 & 2695.094 & 2695.094 & 2752.284 & 0.0001 \\
\hline$x_{1}^{2}$ & 1 & 11.7921 & 11.7921 & 1.2817 & 0.3089 & 1 & 59.1641 & 59.1641 & 4.4183 & 0.0895 & 1 & 32.5042 & 32.5042 & 33.1939 & 0.0022 \\
\hline$x_{1} x_{2}$ & 1 & 88.9541 & 88.9541 & 9.6682 & 0.0266 & 1 & 19.2971 & 19.2971 & 1.4411 & 0.2837 & 1 & 4.2117 & 4.2117 & 4.3011 & 0.0928 \\
\hline$x_{1} x_{3}$ & 1 & 7.6948 & 7.6948 & 0.8363 & 0.4024 & 1 & 39.3606 & 39.3606 & 2.9394 & 0.1471 & 1 & 11.4792 & 11.4792 & 11.7228 & 0.0188 \\
\hline$x_{2}^{2}$ & 1 & 31.4468 & 31.4468 & 3.4179 & 0.1237 & 1 & 194.8759 & 194.8759 & 14.553 & 0.0124 & 1 & 209.5919 & 209.5919 & 214.0395 & 0.0001 \\
\hline$x_{2} x_{3}$ & 1 & 359.6997 & 359.6997 & 39.0950 & 0.0015 & 1 & 121.2616 & 121.2616 & 9.0556 & 0.0298 & 1 & 55.6919 & 55.6919 & 56.8737 & 0.0006 \\
\hline$x_{3}^{2}$ & 1 & 0.1271 & 0.1271 & 0.0138 & 0.911 & 1 & 159.5908 & 159.5908 & 11.918 & 0.0182 & 1 & 115.3836 & 115.3836 & 117.8321 & 0.0001 \\
\hline Residual & 5 & 46 & 9.2 & & & 5 & 66.95 & 13.39 & & & 5 & 4.9 & 0.98 & & \\
\hline Lack of Fit & 3 & 42.4 & 14.13 & 7.84 & 0.115 & 3 & 60.58 & 20.19 & 6.33 & 0.139 & 3 & 3.86 & 1.29 & 2.47 & 0.301 \\
\hline Pure Error & 2 & 3.6 & 1.80 & & & 2 & 6.38 & 3.19 & & & 2 & 0.39 & 0.52 & & \\
\hline Total & 14 & 6253.94 & & & & 14 & 8165.31 & & & & 14 & 6666.28 & & & \\
\hline
\end{tabular}

DF: degrees of freedom of variance source; SS: sum of squares; MS: mean of squares (=SS/DF); $F$ : $F$-value of variance source =MS/MSres; $P$ : probability of error to be significant. The numbers indicated as subscript of $F$ are degrees of freedom of variance source (i.e. regression, lack of fit) and degree of freedom of error, respectively. 
Table 5 Comparison of experimental and predicated values of three responses at the optimal conditions by RSM

\begin{tabular}{|c|c|c|c|c|}
\hline \multirow[b]{2}{*}{ P source } & \multirow[b]{2}{*}{ Optimal conditions } & \multicolumn{2}{|c|}{ Responses (\%) } & \multirow{2}{*}{$\begin{array}{l}\text { Error } \\
(\%)\end{array}$} \\
\hline & & Predicted values & $\begin{array}{c}\text { Experimental } \\
\text { value }\end{array}$ & \\
\hline & $\mathrm{pH}=4.20$ & & & \\
\hline Ortho-P & $\begin{array}{l}\text { PAS mass }=0.49 \mathrm{~g} \\
\text { PAS size }=125 \mu \mathrm{m} \\
\mathrm{pH}=4.27\end{array}$ & 99.8 & 99.6 & 0.2 \\
\hline Poly-P & $\begin{array}{l}\text { PAS mass }=0.47 \mathrm{~g} \\
\text { PAS size }=125 \mu \mathrm{m} \\
\mathrm{pH}=4.17\end{array}$ & 94.9 & 92.1 & 3.0 \\
\hline Organic-P & $\begin{array}{l}\text { PAS mass }=0.47 \mathrm{~g} \\
\text { PAS size }=125 \mu \mathrm{m}\end{array}$ & 94.8 & 94.2 & 0.7 \\
\hline
\end{tabular}




\section{Figure Captions}

Fig. 1. The observed values (\%) plotted against the predicated values (\%) derived from the models of $Y_{1}, Y_{2}$ and $Y_{3}$ in uncoded values. The long dash line is $\mathrm{y}=\mathrm{x}$. Each point refers to the experimental number listed in Table 2.

Fig. 2. Response surface and contour plots of ortho-P removal $\left(Y_{1}, \%\right)$ in uncoded values for $\mathrm{t}=2 \mathrm{~h}$. (a) $\mathrm{pH}$ and PAS mass being fixed, and PAS size at $273 \mu \mathrm{m}$, (b) PAS mass and PAS size being fixed, and $\mathrm{pH}$ at 5.5, (c) $\mathrm{pH}$ and PAS size being fixed, and PAS mass at $0.3 \mathrm{~g}$.

Fig. 3. Response surface and contour plots of poly-P removal $\left(Y_{2}, \%\right)$ in uncoded values for $\mathrm{t}=2 \mathrm{~h}$. (a) $\mathrm{pH}$ and PAS mass being fixed, and PAS size at $273 \mu \mathrm{m}$, (b) PAS mass and PAS size being fixed, and $\mathrm{pH}$ at 5.5, (c) $\mathrm{pH}$ and PAS size being fixed, and PAS mass at $0.3 \mathrm{~g}$.

Fig. 4. Response surface and contour plots of organic-P removal $\left(Y_{3}, \%\right)$ in uncoded values for $\mathrm{t}=2 \mathrm{~h}$. (a) $\mathrm{pH}$ and PAS mass being fixed, and PAS size at $273 \mu \mathrm{m}$, (b) PAS mass and PAS size being fixed, and $\mathrm{pH}$ at 5.5, (c) $\mathrm{pH}$ and PAS size being fixed, and PAS mass at $0.3 \mathrm{~g}$. 

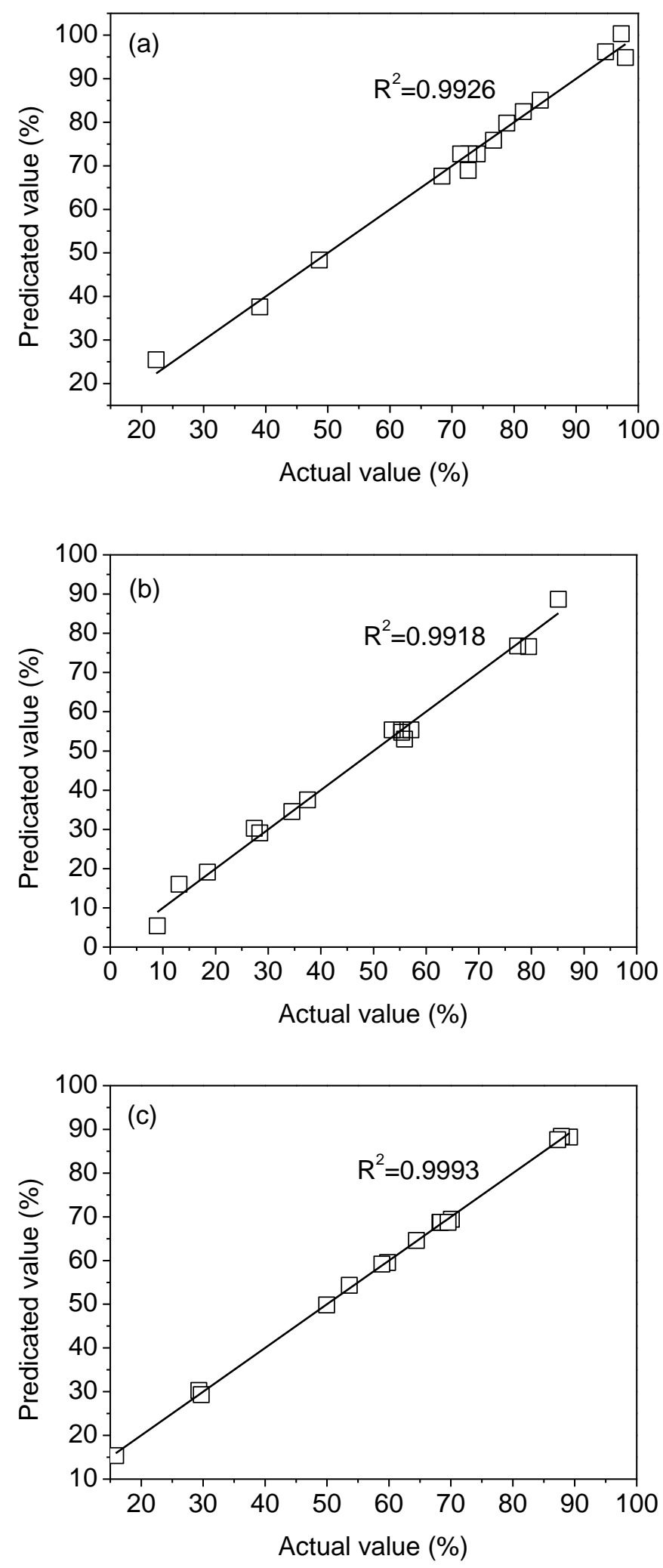

Fig. 1 

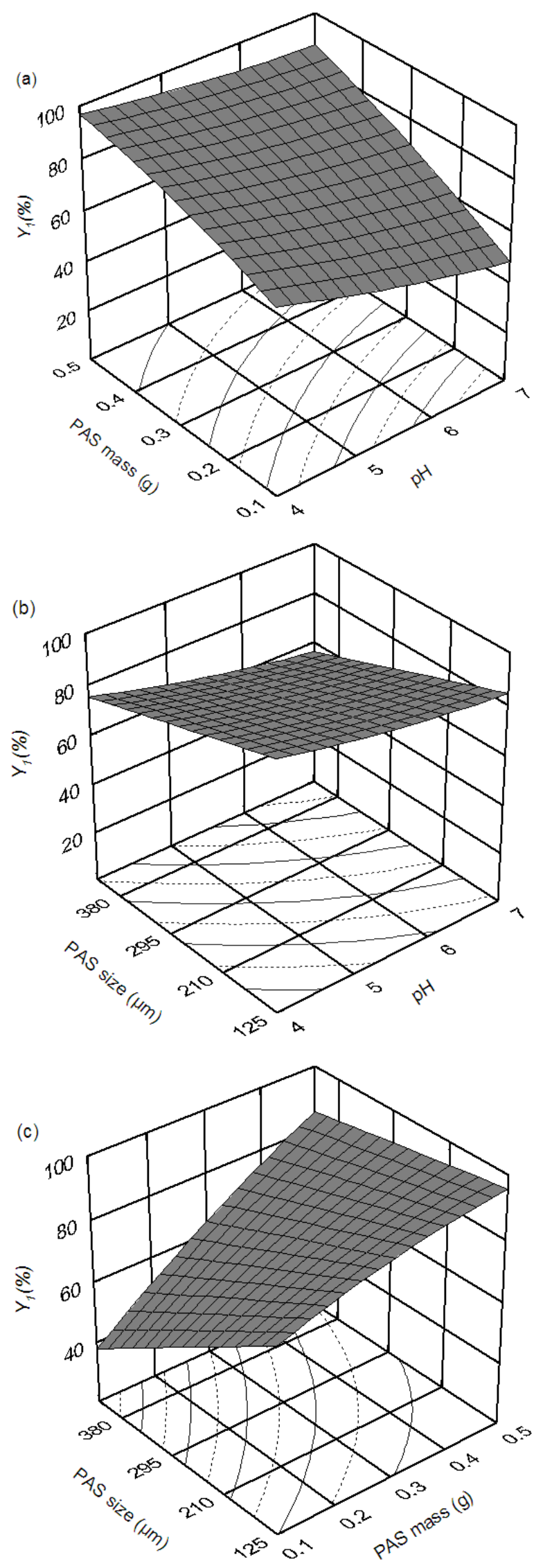

Fig. 2 

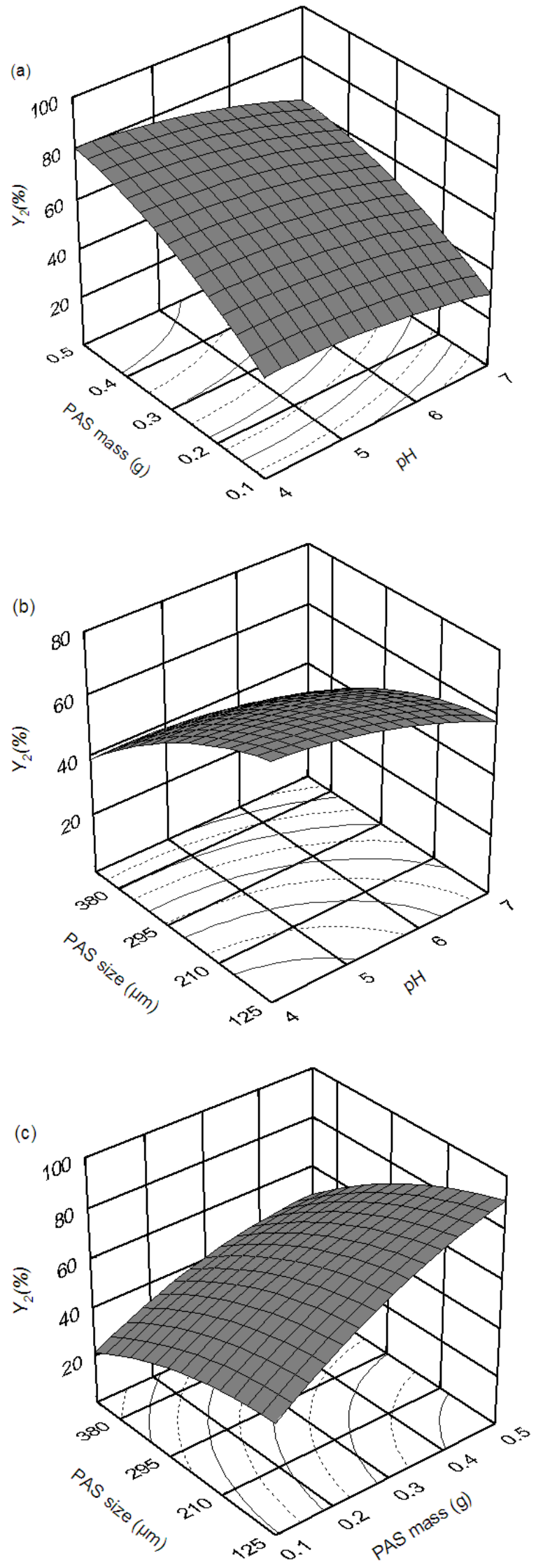

Fig. 3 

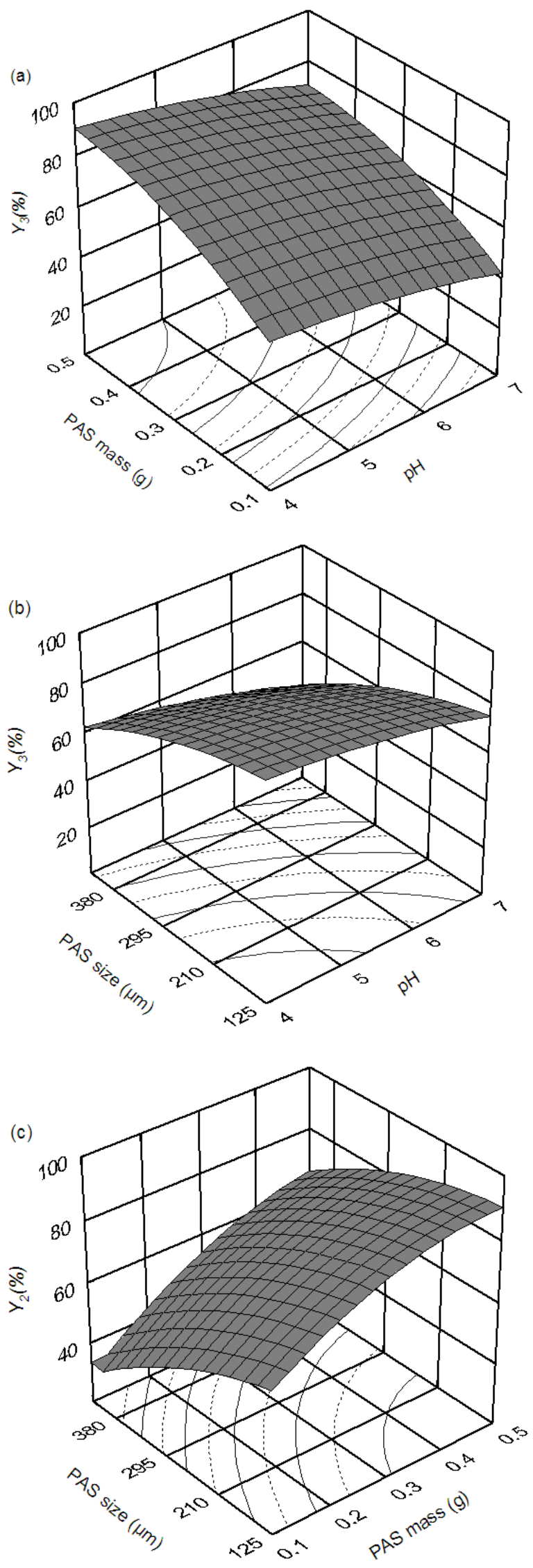

Fig. 4 